\title{
Contraceptive use and preference of HIV infected pregnant women living with HIV-negative partners in the central region of Cameroon: a cross sectional survey
}

\section{Martin Kuete}

Anhui Biochem United Pharma

Hilary Christiane Sipeuwou Ngueye

Universite des Montagnes Faculte des Sciences de la Sante

Sean Zhe Wang

Anhui Biochem United Pharma Co.

\section{HongFang Yuan}

Huazhong University of Science and Technology Tongji Medical College

\section{XiuLan Ma}

Central Hospital of Wuhan, Department Obstetric and Gynecology

Christine Mandengue

Universite des Montagnes Faculte des Sciences de la Sante

Berthine Marie Miste Ndaya

Central Hospital of Yaounde, Main maternity

Yannick Zomnyate Nyangono

Universite des Montagnes Faculte des Sciences de la Sante

Carrel Raspail Founou Zangue

Centre of expertise and biological diagnostic of Cameroon

ChengLiang Xiong

Family Planning and Reproductive Institute

HuiPing Zhang ( $\nabla$ familyplanning2013@163.com )

Huazhong University of Science and Technology Tongji Medical College

\section{Research article}

Keywords: Contraception, preferences, HIV-positive women, Cameroon

Posted Date: August 23rd, 2019

DOI: https://doi.org/10.21203/rs.2.13501/v1

License: @ (i) This work is licensed under a Creative Commons Attribution 4.0 International License. Read Full License 


\section{Abstract}

Background Evidences in sub-Saharan Africa including Cameroon indicate that most of HIV discordant couples want more children despite their HIV status. Investigate and establish contraception preferences among HIV infected individuals are fundamental and crucial to provide effective reproductive healthcare.Methods We performed a cross-sectional study using structured questionnaire to explore HIV-positive pregnant women patterns including their family planning services, their preferences and its use, and their knowledge related to HIV/AIDS. Bivariate and multivariate analyses were conducted to explore associations and predictors of contraception preference and use; all tests were two sided significant at $\mathrm{P}<0.05$. Results Overall, $94 \mathrm{HIV-positive} \mathrm{pregnant}$ women aged $30.70 \pm 5.50$ years living with HIV-negative partners were from the different areas of the central region of Cameroon. Three-fourths were aware of the effectiveness of modern contraceptives and condoms, and only $28 \%$ had experienced modern contraption. $98 \%$ preferred to use traditional methods associated with infrequent condoms use. Multiple sociodemographic factors (marital status, group age, educational level, religion, occupation) affected contraceptive method preferences and its use $(\mathrm{P}<0.05)$. These factors are the landmarks to predict discordant couples' behavior in HIV disclosure, discussion and decision making for contraception, preventing mother to-child transmission and HIV-negative partner infection $(P<0.05)$.Conclusion Despite the awareness of participants related both on contraception methods and HIV/AIDS matters, participants faced societal, cultural and demographic barriers to make own decision for contraception use. Promoting effective family planning services and given the entire range of contraception options may help women living with HIV to choose for effective ones and consequently reduce newly HIV infections.

\section{Background}

All women, including those living with HIV infection should be given the opportunity to plan their pregnancies [1]. In 2000, the United Nation launched the historical Millennium Development Goals including within its goals 4, 5 and 6 the hope to improve child and maternal health conditions worldwide by 2015 [2]. Since three decades, many studies have described the trends of the family planning (FP) in the developing world, their unfulfilled needs and the strong demand of contraception [3-6]. To date globally, contraception use has increased and fewer countries in sub-Saharan Africa (SSA) have made greater progress $[1,4,7-9]$. Nevertheless, the total fertility rate is still high indicating that only $26 \%$ of women aged $15-49$ married or in union are using any method of contraception and only $50 \%$ of them attended four or more antenatal care visits [2]. SSA is known as the epicenter of HIV/AIDS epidemic. In 2014, women living with HIV in SSA accounted for $58 \%$ of the total number of PLHIV and among pregnant of them, more than $32 \%$ do not receive any antiretroviral therapy at least to reduce vertical transmission $[1,10,11]$. Additionally, evidences indicate that most of women infected with HIV living in union with HIV-negative individuals in Africa continue to desire and bear more children despite their HIV status [8, 12-18]. Despite the widespread acceptance of family planning services (FPS) is high in some low income countries, the use of contraceptive methods still remains lowest in most of SSA countries including Cameroon [9, 16, 19-21]. In this context, FPS emphasizes prevention of unplanned pregnancies, but occasionally also account for the childbearing desires of HIV clients. In addition, preventing unwanted pregnancies among women living with HIV is the second pillar for PMTCT programme of HIV/AIDS in limited resources settings but its potential has rarely been fully utilized [22, 23]. Since decades, the fertility rate of about 5.8 in Cameroon is one of highest worldwide with an approximate of 782 women dying from pregnancy or delivery related causes per 100,000 live births [8, 24, 25]. $72 \%$ of 2.3 million sexually active Cameroonian women wanted to delay or have no more children. Analyses also demonstrated that $63 \%$ of women who want to avoid pregnancy do not use a modern contraceptive method, so the use of the reproductive assistance and specifically FP services are insignificant [19, 26-28]. It is estimated that if all unmet needs are satisfied, still contraceptive prevalence would reach only $46 \%[8,24]$, but it is almost twice the current level. Currently, fewer data from demographic health surveys (DHS) and unpublished studies appraise that two-thirds of infected couples are serodiscordant in Cameroon [24, 25, 29]. The uninfected partners of discordant couples are in high risks of acquiring HIV and the vertical transmission rate is still high. Despite the fact of the underestimated number of discordant couples in this context, safer reproductive choice cannot be ignored by health decision makers and government because of fundamental human rights. Apart data from DHS, no existing study examined the contraceptive use among individuals infected with HIV in Cameroon. The aim of this study was to assess the contraceptive preferences of HIV-positive pregnant women living with HIV-negative individuals.

\section{Methods}

\section{Study design and data collection}

We performed a cross-sectional study using structured questionnaire based on the literature review of prior and similar studies. The study took place at Yaounde Central Hospital, Cameroon. The questionnaire was divided into three sections. The section I focused on socio-demographic data. The sections II explored FP services, preference and its use; and III assessed participants' knowledge related to HIV/AIDS. The inclusion criteria were: (1) HIV-positive pregnant women within the age of 15-49 years; (2) pregnancy derived from of union with HIV-negative partner; (3) women had attended the health facilities for at least six months; (4) patients who were not ill and; (5) provide informed consent. In-depth face-to-face interviews were conducted in English or French depending on the respondents' language ability. The questionnaires were pilot tested in both languages prior to data collection. The study was conducted by the principal investigator and two other trained research assistants, a clinical physician and a midwife working permanently in HIV clinic and family planning and PMTCT units.

\section{Measures}

\section{Socio-demographic characteristics}

The following factors were included as independent variables: age, marital status, religion, education, occupation, residence, possession of cell phone, partner education and occupation. 
Participant's knowledge on contraception included: male and female condoms, pills, intra uterine devise (IUD), injectables, implants, male and female sterilization methods, lactational amenorrhea method (LAM), fertility awareness based method, withdrawal, diaphragm, foam/jelly, emergency contraception and abstinence. Preference and use referred to the type of contraceptive chosen and currently use. Additionally, it included future fertility intentions, the discussion and the factors that may affect contraception use and eventually the need of FP services within discordant couples.

\section{Knowledge on HIV/AIDS}

This section included the HIV status disclosure, knowledge on mother-to-child and sexual partner transmission timings and finally the PMTCT.

\section{Ethical Considerations}

The study was successively approved by the ethical committee of the Family Planning and Reproductive Medicine Institute of Tongji Medical College/Huazhong University of Science and Technology and the Institutional Reviewer Board of Yaounde Central Hospital (IRB No $653 L / M I N S A N T E / S G / D H C Y$ ) for data collection. All the participants provided a writing informed consent.

\section{Data analysis}

Descriptive statistics were used to examine the distributions and frequencies of participants' characteristics. All the analyses were performed with SPSS software (version 17.0, SPSS Inc., Chicago, IL.). Chi-squared and Fisher's Exact tests were used to assess whether sociodemographic characteristics were associated to contraceptive methods preferences and its effective use and also to HIV infection patterns (HIV status disclosure to the sexual partner, prevention of mother-to-child transmission). Participants' knowledge on existing contraceptive methods were assessed using simple dichotomous variables (Yes/No); then, proportions given in percentages estimated their awareness. Further, contraceptives were organised into condoms use, modern contraceptives and traditional contraceptives use. Furthermore, socio-demographics settings were considered as independent variables to draw associations with the contraception use, the factors influencing the discussion of contraceptive use and HIV disclosure within couples. All the statistical tests were two sided with a significance level at $P<0.05$.

Results

\section{Participants' socio-demographic characteristics and their contraception knowledge}

The mean age of the 94 HIV positive pregnant women who reported living with HIV negative partner was $30.70 \pm 5.50$ years and ranged $18-40$ years. $69 \%$ of women were married and $27 \%$ were divorced/widowed. The majority of respondents were christian while nearly half have attended the secondary education Occupationally, $50 \%$ of respondents earn a monthly salary while the other $50 \%$ were housewives. $77 \%$ of participants were living in urban area. Concerning their partner education, approximatively $43 \%$ have completed the secondary education while $25 \%$ attended higher school and $63 \%$ were workers. All the surveyed women had already heard about FP services; while one woman and four others did not recognize male condom and female condom like contraceptive methods respectively. Concerning the modern contraception, more than three-fourths cited pills, emergency contraception, IUD, injectables, implants, whereas nearly one-third cited male and female sterilization methods. Although, only 2 women knew the diaphragm method and none knew the foam/jelly. Regarding the traditional methods, more than two-thirds (92\%) likely considered abstinence, withdrawal (89\%) and fertility awareness based method as contraception. Moreover, only one-third reported lactational amenorrhea method as contraception.

\section{Family planning services: Current contraceptive use among discordant couples}

Our results found that $96 \%$ of women primary preferred condoms. Only $28 \%$ were currently using a modern contraceptive while approximatively $98 \%$ preferred traditional contraceptive. Nearly one third of women have never discussed FP concerns with their partners while $31 \%$ expressed no need of FP services in their household. The results summarized in Table 1 showed that Christians were more likely to use condom than Muslims and women affiliated to other religions $(P$ $<0.05)$; additionally, unemployed women were less likely to use condoms compared to their counterparts $(P<0.05)$. The women in relationship with welleducated partners were more likely to use emergency contraception $(P=0.005)$, although less prefer to use implants. Contrary to previous variables affecting modern contraceptives use, the current study indicated that marital status may affect the usage of LAM and FABM as contraception $(P<0.05)$. Married 
women were more likely to adopt these methods compared to others. Furthermore, most of women who achieved the secondary education mainly adopted abstinence $(P=0.01)$.

Table 1 Relationship between socio-demographic characteristics and contraception used of pregnant women infected of HIV

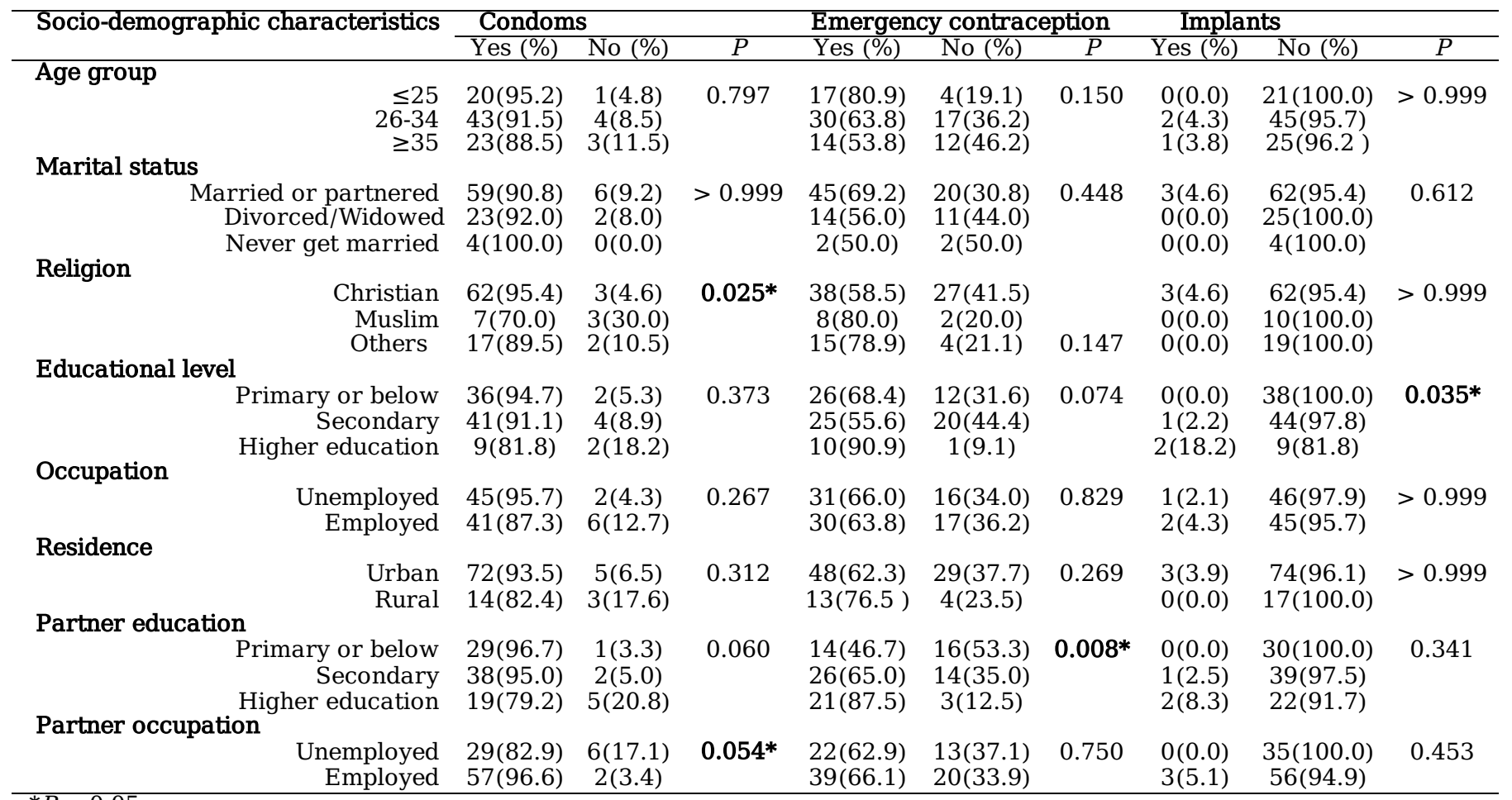

$* P<0.05$

Table 1 (continued) Relationship between socio-demographic characteristics and contraception used by pregnant women infected of HIV

\begin{tabular}{|c|c|c|c|c|c|c|c|c|c|}
\hline \multirow{2}{*}{ Socio-demographic characteristics } & \multicolumn{3}{|c|}{ LAM } & \multicolumn{3}{|c|}{ Rhythm method or FABM } & \multicolumn{2}{|c|}{ Abstinence } & \multirow[b]{2}{*}{$P$} \\
\hline & Yes (\%) & No $(\%)$ & $P$ & Yes (\%) & No (\%) & $P$ & Yes (\%) & No (\%) & \\
\hline Age group & & & & & & & & & \\
\hline$\leq 25$ & $6(28.6)$ & $15(71.4)$ & 0.308 & 13(61.9) & $8(38.1)$ & 0.700 & 19(90.5) & $2(9.5)$ & 0.709 \\
\hline $26-34$ & $14(29.8)$ & $33(70.2)$ & & $27(57.5)$ & $20(42.5)$ & & $44(93.6)$ & $3(6.4)$ & \\
\hline$\geq 35$ & $12(46.2)$ & $14(53.8)$ & & $13(50.0)$ & $13(50.0)$ & & $23(88.5)$ & $3(11.5)$ & \\
\hline \multicolumn{10}{|l|}{ Marital status } \\
\hline Married or partnered & $29(44.6)$ & $36(55.4)$ & $0.003^{*}$ & $35(53.8)$ & $30(46.2)$ & $0.017 *$ & $61(93.8)$ & $4(6.2)$ & 0.361 \\
\hline Divorced/Widowed & $3(12.0)$ & $22(88.0)$ & & 18(72.0) & $7(28.0)$ & & $21(84.0)$ & $4(16.0)$ & \\
\hline \multirow{2}{*}{\multicolumn{10}{|c|}{ ivever get mantred }} \\
\hline & & & & & & & & & \\
\hline Christian & $23(35.4)$ & $42(64.6)$ & 0.916 & $34(52.3)$ & $31(47.7)$ & 0.233 & $61(93.8)$ & $4(6.2)$ & 0.230 \\
\hline Muslim & $3(34.0)$ & $7(66.0)$ & & $5(50.0)$ & $5(50.0)$ & & $8(80.0)$ & $2(20.0)$ & \\
\hline Others & $6(31.58)$ & $13(68.4)$ & 0.916 & $14(73.7)$ & $5(26.3)$ & 0.233 & 17(89.5) & $2(10.5)$ & 0.230 \\
\hline \multicolumn{10}{|l|}{ Educational level } \\
\hline Primary or below & 13(34.2) & $25(65.8)$ & 0.667 & $23(60.5)$ & $15(39.5)$ & 0.288 & $34(89.5)$ & $4(10.5)$ & 0.876 \\
\hline Secondary & 14(31.1) & $31(68.9)$ & & $22(48.9)$ & 23(51.1) & & $42(93.3)$ & $3(6.7)$ & \\
\hline Higher education & $5(34.0)$ & $6(66.0)$ & & $8(72.7)$ & $3(27.3)$ & & $10(90.9)$ & $1(9.1)$ & \\
\hline \multicolumn{10}{|l|}{ Occupation } \\
\hline Unemployed & $19(40.4)$ & $28(59.6)$ & 0.192 & $25(53.2)$ & $22(46.8)$ & 0.533 & $43(91.5)$ & $4(8.5)$ & 1.000 \\
\hline Employed & $13(27.7)$ & $34(72.3)$ & & $28(59.6)$ & $19(40.4)$ & & $43(91.5)$ & $4(8.5)$ & \\
\hline \multicolumn{10}{|l|}{ Residence } \\
\hline Urban & $28(36.4)$ & $49(63.6)$ & 0.312 & $41(53.2)$ & $36(46.8)$ & 0.192 & $70(90.9)$ & $7(9.1)$ & 1.000 \\
\hline Rural & $4(23.5)$ & $13(76.5)$ & & $12(70.6)$ & $5(29.4)$ & & $16(94.1)$ & $1(5.9)$ & \\
\hline \multicolumn{10}{|l|}{ Partner educational level } \\
\hline Primary or below & $8(26.7)$ & $22(73.3)$ & 0.586 & $15(50.0)$ & $15(50.0)$ & 0.562 & $26(86.7)$ & $4(13.3)$ & $0.013 *$ \\
\hline Secondary & $15(37.5)$ & $25(62.5)$ & & $25(62.5)$ & $15(37.5)$ & & $40(100.0)$ & $0(0.0)$ & \\
\hline Higher education & $9(37.5)$ & $15(62.5)$ & & $13(54.2)$ & $11(45.8)$ & & $20(83.3)$ & $4(16.7)$ & \\
\hline \multicolumn{10}{|l|}{ Partner occupation } \\
\hline Unemployed & $10(28.6)$ & $25(71.4)$ & 0.389 & $22(62.9)$ & 13(37.1) & 0.330 & $31(88.6)$ & $4(11.4)$ & 0.690 \\
\hline Employed & $22(37.3)$ & $37(62.7)$ & & $31(52.5)$ & $28(47.5)$ & & $55(93.2)$ & $4(6.8)$ & \\
\hline
\end{tabular}

\section{Factors influencing the discussion of contraceptive use and the disclosure of HIV status}

Disclosure of HIV status within discordant couples was approved by $86 \%$ of women whereas $14 \%$ opposed. The results presented in Table 2 showed that factors such as age, marriage, education and occupation were significantly associated both in the discussion of contraception and the disclosure of HIV status within couples. 
Table 2 Factors influencing the discussion of contraceptive use and the disclosure of HIV status

\begin{tabular}{|c|c|c|c|c|c|c|}
\hline \multirow{2}{*}{ Variables } & \multicolumn{4}{|c|}{ Discussion of contraceptives with partner } & \multicolumn{2}{|c|}{ Disclosure of HIV status } \\
\hline & Yes (\%) & No (\%) & $P$ & Yes (\%) & No (\%) & $P$ \\
\hline \multicolumn{7}{|l|}{ Age group } \\
\hline$\leq 25$ & $12(57.1)$ & $9(42.9)$ & $0.046^{*}$ & $19(90.5)$ & $2(9.5)$ & 0.421 \\
\hline $26-34$ & $27(57.5)$ & $20(42.5)$ & & $38(80.8)$ & $9(19.2)$ & \\
\hline$\geq 35$ & $22(84.6)$ & $4(15.4)$ & & $24(92.3)$ & $2(7.7)$ & \\
\hline Marital status & $44(677)$ & $21(323)$ & 0620 & $59(907)$ & $6(92)$ & 0121 \\
\hline Divorced/Widowed & $15(60.0)$ & $10(40.0)$ & & $19(76.0)$ & $6(24.0)$ & \\
\hline Never get married & $2(50.0)$ & $2(50.0)$ & & $3(75.0)$ & $1(25.0)$ & \\
\hline \multicolumn{7}{|l|}{ Religion } \\
\hline Christian & $45(69.2)$ & $20(30.8)$ & 0.194 & $56(86.2)$ & $9(13.8)$ & $>0.999$ \\
\hline Muslim & $4(40.0)$ & $6(60.0)$ & & $9(90.0)$ & $1(10.0)$ & \\
\hline Others & $12(63.2)$ & $7(36.8)$ & & $16(84.2)$ & $3(15.8)$ & \\
\hline \multicolumn{7}{|l|}{ Educational level } \\
\hline Primary or below & $29(76.2)$ & $9(23.8)$ & 0.142 & $31(81.6)$ & $7(18.4)$ & 0.560 \\
\hline Secondary & $25(55.6)$ & $20(44.4)$ & & $40(88.9)$ & $5(11.1)$ & \\
\hline Higher education & $7(63.6)$ & $4(36.4)$ & & $10(90.9)$ & $1(9.1)$ & \\
\hline \multicolumn{7}{|l|}{ Occupation } \\
\hline Employed & $29(61.7)$ & $18(38.3)$ & & $37(78.7)$ & $10(21.3)$ & \\
\hline \multicolumn{7}{|l|}{ Residence } \\
\hline Urban & $50(64.9)$ & $27(35.1)$ & 0.986 & $69(89.6)$ & $8(10.4)$ & 0.095 \\
\hline Rural & $11(64.7)$ & $6(35.3)$ & & $12(70.6)$ & $5(29.4)$ & \\
\hline \multicolumn{7}{|l|}{ Partner education } \\
\hline Primary or below & $22(73.3)$ & $8(26.7)$ & 0.183 & $26(86.7)$ & $4(13.3)$ & 0.929 \\
\hline Higher education & $12(50.0)$ & $12(50.0)$ & & 20(83.3) & $\begin{array}{l}5(12.5) \\
4(16.7)\end{array}$ & \\
\hline \multicolumn{7}{|l|}{ Partner occupation } \\
\hline Unemployed & $22(62.6)$ & $13(37.4)$ & 0.750 & $32(91.4)$ & $3(8.6)$ & 0.407 \\
\hline Employed & $39(66.1)$ & $20(33.9)$ & & $49(83.1)$ & $10(16.9)$ & \\
\hline
\end{tabular}

\section{Contraceptive use in accordance to joint decision of couples for future fertility}

This study assessed both the use of traditional and modern contraceptives among discordant couples. Despite the fact that a large majority of women preferred traditional contraception, only condoms usage was significantly associated with the partners' decision $(P=0.013)$. The lack of knowledge was the main reason for effective contraception non-use $(P<0.001)$ (see Table 3)..

Table 3 Contraceptive use in accordance to joint decision of couples for future fertility 


\begin{tabular}{|c|c|c|c|}
\hline Current method to avoid pregnancies & Yes (\%) & No (\%) & $P$ \\
\hline \multicolumn{4}{|l|}{ Condoms (male and female) } \\
\hline yes & $42(48.8)$ & $44(51.2)$ & $0.013^{*}$ \\
\hline no & $3(37.5)$ & $5(62.5)$ & \\
\hline \multicolumn{4}{|l|}{ Pills } \\
\hline yes & $12(46.2)$ & $14(53.8)$ & 0.837 \\
\hline no & $33(48.5)$ & $35(51.5)$ & \\
\hline \multicolumn{4}{|l|}{ Intrauterine devise } \\
\hline yes & 1(33.3) & $2(66.7)$ & $>0.999$ \\
\hline no & $44(48.4)$ & $47(51.6)$ & \\
\hline \multicolumn{4}{|l|}{ Injectable } \\
\hline yes & $4(57.1)$ & $3(42.9)$ & 0.907 \\
\hline no & $41(47.1)$ & $46(52.9)$ & \\
\hline \multicolumn{4}{|l|}{ Implants } \\
\hline yes & $2(66.7)$ & $1(33.3)$ & 0.940 \\
\hline no & $44(47.3)$ & $49(52.7)$ & \\
\hline \multicolumn{4}{|l|}{ Awareness fertility method } \\
\hline yes & $26(49.1)$ & $27(50.9)$ & 0.794 \\
\hline no & $19(46.3)$ & $22(53.7)$ & \\
\hline \multicolumn{4}{|l|}{ Lactational amenorrhea method } \\
\hline $\begin{array}{ll}\text { yes }\end{array}$ & $1(20.0)$ & $4(80.0)$ & 0.410 \\
\hline no & $44(49.4)$ & $45(50.6)$ & \\
\hline \multicolumn{4}{|l|}{ Withdrawal } \\
\hline yes & $30(51.7)$ & $28(48.3)$ & 0.343 \\
\hline no & $15(41.7)$ & $21(58.3)$ & \\
\hline \multicolumn{4}{|l|}{ Diaphragm } \\
\hline yes & $2(66.7)$ & $1(33.3)$ & 0.940 \\
\hline no & $43(47.3)$ & $48(52.7)$ & \\
\hline \multicolumn{4}{|l|}{ Emergency contraception } \\
\hline yes & $8(47.1)$ & $9(52.9)$ & 0.941 \\
\hline no & $37(48.1)$ & $40(51.9)$ & \\
\hline \multicolumn{4}{|l|}{ Abstinence from sex } \\
\hline yes & $32(50.0)$ & $32(50.0)$ & 0.546 \\
\hline no & $13(43.3)$ & $17(56.7)$ & \\
\hline $\begin{array}{r}\text { Reasons of contraceptives non use } \\
\text { Partner opposition }\end{array}$ & Yes (\%) & No (\%) & $P$ \\
\hline yes & $41(48.2)$ & $44(51.8)$ & $>0.999$ \\
\hline no & $4(44.4)$ & $5(55.6)$ & \\
\hline \multicolumn{4}{|l|}{ Lack of knowledge } \\
\hline yes & $45(56.3)$ & $35(43.7)$ & $0.001 * *$ \\
\hline no & $0(0.0)$ & $14(100.0)$ & \\
\hline
\end{tabular}

$* P<0.05 ; * * P<0.001$

\section{Demographic characteristics affected pregnant women's knowledge related to the period of transmission of HIV from mother-to-child}

The results presented in Table 4 showed that most of women (81\%) identified breastfeeding as the main route of mother-to-child transmission of HIV (MTCT) and $35 \%$ were aware that infection may occur during pregnancy, delivery and breastfeeding. At the time of this survey, $30 \%$ of these HIV infected pregnant women were ART naïve. In short, many socio-demographic characteristics significantly affected participants' knowledge about the period of transmission. Women aged 26-34 reported both vaginal delivery and breastfeeding as major transmission route $(P=0.032)$. Married women were more likely aware of the three main routes MTCT $(P<0.05)$. Additionally, education was significantly associated with knowledge on MTCT $(P<0.05)$.

Table 4 Demographic characteristics affect participants' knowledge related on mother-to-child transmission of HIV 


\begin{tabular}{|c|c|c|c|c|c|c|c|c|c|c|c|c|}
\hline & During d & divery & & During & pregnanc & $y$ and & $\underset{b r}{\text { Durin }}$ & $\begin{array}{l}\text { g delivery } \\
\text { eastfeedin }\end{array}$ & and & $\begin{array}{l}\text { During } \\
\text { br }\end{array}$ & $\begin{array}{l}\text { pregnanc } \\
\text { eastfeedin }\end{array}$ & and \\
\hline Variables & Yes (\%) & No (\%) & $P$ & Yes (\%) & No (\%) & $P$ & Yes (\%) & No (\%) & $P$ & Yes (\%) & No (\%) & $P$ \\
\hline Age group & $13(61.9)$ & $8(38.1)$ & 0.084 & $13(61.9)$ & $8(38.1)$ & 0.978 & $11(52.4)$ & $10(47.6)$ & $0.032 *$ & $6(28.6)$ & $15(71.4)$ & $0.77 t$ \\
\hline $26-34$ & & & & & $19(40.4)$ & & $27(42.5)$ & $20(57.5)$ & & $16(34.1)$ & & \\
\hline $\begin{array}{r}\geq 35 \\
\text { arital status }\end{array}$ & $23(88.5)$ & $3(11.5)$ & & $16(61.5)$ & $10(38.5)$ & & $22(84.6)$ & $4(15.4)$ & & $10(38.5)$ & $16(61.5)$ & \\
\hline Married or & $53(81.5)$ & 12(18.5) & $0.012^{*}$ & $35(53.9)$ & $30(46.1)$ & 0.113 & $48(73.8)$ & $17(26.2)$ & $0.007 *$ & $27(41.5)$ & $38(58.5)$ & $0.04 \varepsilon$ \\
\hline Divorced/Widowed & $13(52.0)$ & $12(48.0)$ & & 19(76.0) & $6(24.0)$ & & $10(40.0)$ & $15(60.0)$ & & $4(16.0)$ & $21(84.0)$ & \\
\hline $\begin{array}{r}\text { Never married } \\
\text { Religion }\end{array}$ & $2(50$ & $2(50$ & & $3(75.0)$ & $1(25.0)$ & & $2(50.0)$ & $2(50.0)$ & & $1(75.0)$ & $3(75.0)$ & \\
\hline Christian & $54(83.1)$ & $11(16.9)$ & $0.002 *$ & $28(43.1)$ & $37(56.9)$ & 0.421 & $48(73.8)$ & $17(26.2)$ & $0.002 *$ & $25(38.5)$ & $40(61.5)$ & $0.37^{\prime}$ \\
\hline & & & & & & & $2(20.0)$ & & & & & \\
\hline Others & $10(52.6)$ & $9(47.4)$ & & $5(26.3)$ & $14(73.7)$ & & $10(52.6)$ & $9(47.4)$ & & $5(26.3)$ & $14(73.7)$ & \\
\hline $\begin{array}{l}\text { Educatio } \\
\text { Primary }\end{array}$ & $24(632)$ & $14(368)$ & 0252 & $10(26.3)$ & $28(737)$ & $0018 *$ & 2105 & & 0326 & & & \\
\hline $\begin{array}{l}\text { Secondary } \\
\text { Higher education }\end{array}$ & $35(77$. & $10(22$ & & $19(42.2)$ & $26(57.8)$ & $0.010^{\circ}$ & $32(71.1)$ & $13(28.9)$ & 0.326 & $17(37.8)$ & $\begin{array}{l}30(78.9) \\
28(62.2)\end{array}$ & 0.024 \\
\hline $\begin{array}{r}\text { Higher education } \\
\text { Occupation }\end{array}$ & $9(81.8)$ & $2(18.2$ & & $8(72.7)$ & $3(27.3)$ & & $7(63.6)$ & $4(36.4)$ & & $7(63.6)$ & $4(36.4)$ & \\
\hline Unemployed & $34(72.3)$ & $13(27.7)$ & 0.999 & $16(34.1)$ & $31(65.9)$ & 0.291 & $31(65.9)$ & $16(34.1)$ & 0.668 & $33(70.2)$ & $14(29.8)$ & 0.38 \\
\hline $\begin{array}{l}\text { Employed } \\
\text { Residence }\end{array}$ & $34(72.3)$ & $13(27.7)$ & & 21(44.7) & $26(55.3)$ & & $29(61.7)$ & $18(38.3)$ & & $29(61.7)$ & 18(38.3) & \\
\hline $\begin{array}{l}\text { Urban } \\
\text { Rural }\end{array}$ & $\begin{array}{l}57(74.1) \\
11(64.7)\end{array}$ & $\begin{array}{l}20(25.9) \\
6(35.3)\end{array}$ & 0.633 & $\begin{array}{l}46(59.7) \\
11(64.7)\end{array}$ & $\begin{array}{l}31(40.3) \\
6(35.3)\end{array}$ & 0.704 & $\begin{array}{c}52(67.5) \\
8(47.1)\end{array}$ & $\begin{array}{l}25(32.5) \\
9(52.9)\end{array}$ & 0.112 & $\begin{array}{l}27(35.1) \\
5(29.4)\end{array}$ & $\begin{array}{l}50(64.9) \\
12(70.6)\end{array}$ & $0.65 t$ \\
\hline Partner education & & & & & & & & & & & & \\
\hline $\begin{aligned} i m a r y \\
S\end{aligned}$ & $24(80.0)$ & $6(20$ & 0.360 & $12(40.0)$ & $18(60.0)$ & 0.159 & $21(70.0)$ & $9(30$. & 0.529 & $10(33.3)$ & 20(66.7) & 0.32 \\
\hline $\begin{array}{r}\text { Secondary } \\
\text { Higher education }\end{array}$ & & & & & & & & & & & & \\
\hline $\begin{array}{r}\text { Higner equcation } \\
\text { Partner } \\
\text { occupation }\end{array}$ & & & & & 11 (45.0) & & & & & & & \\
\hline Unem & $25(71.4)$ & & 0.879 & & & 0.922 & & & 0.880 & & & $0.96 !$ \\
\hline & & & & & & & & & & & & \\
\hline
\end{tabular}

\section{Discussion}

The two-thirds of HIV infected pregnant women living with HIV-negative partners found in this study were similar to other previous findings in SSA [8, 14, 28]. Regarding the substantial proportion of divorced and widowed women pregnant at the time of this study, it appeared that infected women were less concerned of their partners' risk exposure; since their fertility intentions seemed more important. Our findings indicated that stable union and higher level of education enhance women awareness related to contraception. Conversely, we speculate that socio-demographic characteristics may positively or negatively impact reproductive health of infected women. Therefore, understanding the dynamic of demographic characteristics by integrating the childbearing counseling with HIV testing may affect both reproductive decision-making and the HIV trends amongst discordant couples. Several researches claimed the overwhelming number of HIV infected women living in SSA with limited options of contraception $[6,8,9,16,30]$. Increasing contraceptive use among discordant couples obviously reduces the HIV-negative partner of contracting the virus, decreases the numbers of unwanted pregnancies and thus reduces maternal deaths and mother-to-child transmission of HIV. Despite the fact that almost all the women were knowledgeable of more efficacious contraception, many still rejected while others who reported an interest faced several barriers to apply. The major reasons given for rejecting the FP services were because of misconceptions, the unavailability of contraceptives in the HIV clinics and the partners' opposition. The utilization of family planning services is lower in Cameroon, only $24 \%$ of women aged 15-49 years are using contraceptives [24]. This study highlights: partners' opposition somehow is associated with violence, the hesitation of women to disclose their HIV status to sexual intimate partner, the choice of traditional contraception (withdrawal, fertility awareness based method, lactational amenorrhea, abstinence) including irregular sexual intercourse. Whatever, infrequent condom usage is useless to prevent unwanted pregnancy and HIV transmission amongst discordant couples; therefore, we argue that women infected of HIV in the center region of country hardly adopt effective modern contraceptives methods detrimental to traditional contraception. Whenever women preferred condom, we observed that almost inconsistently used it for contraception issues and consequently, two life-threatening conditions might result: pregnancy or HIV infection of non-infected partner. However, condoms only protects when used correctly and consistently $[13,14,16]$. Indeed, local government and media made much effort to provide information about contraception especially in the urban settings of Cameroon; our findings help to understand the large gap between awareness and practices among potential contraceptive users. Thoroughly, education and information currently deserved in this context seems to be a virtual concept only and are not enough to raise the behavior change and to adapt effective contraception use among this population. Besides of HIV status disclosure concerns, the proportion of pregnant women without ART despite the policy option B+ found in this study may tend to describe the tendency in others areas of country [25, 26, 31]. Thus, medication certainly counts for HIV prevention but its benefit is limited to cover PLHIV needs in low-resource settings. This observation may call healthcare decision-makers attention regarding some societal, cultural and demographic factors reported as the main barriers of contraception use within discordant couples in this study.

Despite the debatable proportion of women who reported to have discussed contraceptives and disclosed their HIV status to their partners, our findings revealed that women aged above 35 years were more active to debate contraception with their partner than younger ones. Likewise, women without any monthly income were more committed to disclose their HIV status to their partner compared to their counterparts. Male partner plays a major role in each household with special function in African culture, but has rarely been associated in contraception concerns. This study showed the positive effect of marriage, age, education and stable employment in favor of HIV status disclosure and discussion for contraception use amongst discordant couples. We 
assume that discussion and decision making are based not only on demographic characteristics but also on their expectations for future children. Recently, Birhane et al. demonstrated that spouse discussion about MTCT of HIV with sexual partners also increased awareness related to this issue[32].

Likewise due to the spouse's decision, only condom was preferentially used before and after the pregnancy. As other previous studies, we criticize the single condom use as contraception among discordant couples $[6,13]$. However, women reported many constraints such as partner opposition and side effects that influence the non-use of effective contraceptives. Although, there are substantial benefits of modern contraception for discordant couples[8, 33]. Despite the fact that many women infected of HIV in SSA continue to face stigma and discrimination $[9,14,30]$, they are also victim of male violence regarding contraception use [20]. Overall, $64 \%$ of women reported having family planning unmet needs whereas $48 \%$ of pregnancies were unplanned despite the satisfaction of participants; additionally, both single and combined contraceptives were inconsistently used. These results are similar with other previous surveys $[15,17,18,34]$. Those with high fertility intentions were less likely to use condoms consistently during sex with their partner. Our findings add new evidences that sex practices and fertility intentions of discordant couples occur regardless whether one partner is HIV-infected or not.

Despite the differences related on MTCT (pregnancy, delivery or breastfeeding) among participants, we noticed a slight increase of knowledge of respondents compared with the previous results from Bissek et al. assessing the knowledge of pregnant women on MTCT in Yaoundé in 2010 [31]. However, differences observed in identifying the three main routes of transmission could be due to the fact that some of participants were from rural area of the region and may hardly access to the information on HIV. Besides the high educational level that usually increase women awareness on HIV and contraception [26, 27, 32, 35], marriage and group age 26-34 in this study were positively associated with the women full knowledge on the right periods of MTCT. In our knowledge, this finding has not yet been reported in previous studies and further researches are warranted to explore the deep associations between marital status and vertical transmission among discordant couples. We hypothesize that marriage may help couples to be knowledgeable of MTCT. These results highlight the huge and urgent needs of reproductive health programmes and policies to recognize the fertility rights of PLHIV. Promote effective contraception, incorporate and support safer conception services of women living with HIV into maternal cares will certainly decrease the sexual risk behaviour and the MTCT of HIV in Cameroon.

\section{Conclusions}

HIV infected women living with HIV-negative partner are the potential targets to benefit from family planning services both protecting uninfected partner and their children. Discordant couples face several societal, cultural and demographic barriers including lower educational level, male opposition and lack of access to family planning services. Women living with HIV infection should be educated and given the entire range of contraception options to help to choose for effective and comfortable ones. Incorporate services to provide more information and education to discordant couples to prevent both HIV-negative partners and infants infection are needed.

\section{Declarations}

Ethics approval and consent to participate

This survey was approved by the Yaounde Central Hospital IRB No 653L/MINSANTE/SG/DHCY for data collection. All the participants provided a writing informed consent.

\section{Consent for publication}

Not applicable

\section{Availability of data and materials}

The data presented in this paper are freely available upon request.

\section{Availability of data and materials}

The data presented in this paper are freely available upon request.

\section{Competing interests}

The authors declare that they have no competing interests.

\section{Funding}

No funding was received for this study. 
MK and HPZ conceptualized and designed the study materials. MK, HCSN, YZN and BMMN were involved in the acquisition of data. MK and HFY performed the statistical analysis. MK, XLM, and HPZ drafted the manuscript. CM, CLX, CRFZ, and HCSN revised the draft manuscript for intellectual content. HPZ and CLX supervised the study and all authors approved the final manuscript.

\section{Acknowledgements}

Authors gratefully acknowledge the travel support award from Anhui Biochem Bio-Pharmaceutical Company of People's Republic of China. We also thank the clinical staff and participants from Yaounde Central Hospital for their contributions.

\section{References}

1.UNAIDS: The gap report. In., 2014 edn. Geneva, Switzerland: UNAIDS; 2014.

2. The Millennium Development Goals Report 2014 [http://www.un.org/millenniumgoals/2014\%20MDG\%20report/MDG\%202014\%20English\%20web.pdf] 3.Potts DM, Crane SF: Contraceptive delivery in the developing world. British medical bulletin 1993, 49(1):27-39.

4.Frank O: The demand for fertility control in sub-Saharan Africa. Studies in family planning 1987, 18(4):181-201.

5.Bongaarts J, Bruce J: The causes of unmet need for contraception and the social content of services. Studies in family planning 1995, 26(2):57-75.

6.Stuart GS: Fourteen million women with limited options: HIV/AIDS and highly effective reversible contraception in sub-Saharan Africa. Contraception 2009, 80(5):412-416.

7.Dwyer JC, Haws JM: Is permanent contraception acceptable in sub-Saharan Africa? Studies in family planning 1990, 21(6):322-326.

8.Mumah JN, Ziraba AK, Sidze EM: Effect of HIV status on fertility intention and contraceptive use among women in nine sub-Saharan African countries: evidence from Demographic and Health Surveys. Global health action 2014, 7.25579.

9.Emina JB, Chirwa T, Kandala NB: Trend in the use of modern contraception in sub-Saharan Africa: Does women's education matter? Contraception 2014, 90(2):154-161.

10.Takow SE, Atashili J, Enow-Tanjong R, Mesembe MT, Ikomey GM, Ndip LM, Mbuagbaw JC, Ndumbe PM: Time for Option B+? Prevalence and characteristics of HIV infection among attendees of 2 antenatal clinics in Buea, Cameroon. Journal of the International Association of Providers of AIDS Care 2015, 14(1):77-81.

11.Black S, Zulliger R, Marcus R, Mark D, Myer L, Bekker LG: Acceptability and challenges of rapid ART initiation among pregnant women in a pilot programme, Cape Town, South Africa. AIDS care 2014, 26(6):736-741.

12.0'Shea MS, Rosenberg NE, Hosseinipour MC, Stuart GS, Miller WC, Kaliti SM, Mwale M, Bonongwe PP, Tang JH: Effect of HIV status on fertility desire and knowledge of long-acting reversible contraception of postpartum Malawian women. AIDS care 2015, 27(4):489-498.

13.Wagner GJ, Goggin K, Mindry D, Beyeza-Kashesya J, Finocchario-Kessler S, Woldetsadik MA, Khanakwa S, Wanyenze RK: Correlates of Use of Timed Unprotected Intercourse to Reduce Horizontal Transmission Among Ugandan HIV Clients with Fertility Intentions. AIDS and behavior 2014.

14.Ngure K, Baeten JM, Mugo N, Curran K, Vusha S, Heffron R, Celum C, Shell-Duncan B: My intention was a child but I was very afraid: fertility intentions and HIV risk perceptions among HIV-serodiscordant couples experiencing pregnancy in Kenya. AIDS care 2014, 26(10):1283-1287.

15.Asfaw HM, Gashe FE: Fertility intentions among HIV positive women aged 18-49 years in Addis Ababa Ethiopia: a cross sectional study. Reproductive health 2014, 11:36.

16.Ssali A, Namukwaya S, Bufumbo L, Seeley J, D GL, Kamali A, Parkes-Ratanshi R: Pregnancy in HIV clinical trials in Sub Saharan Africa: failure of consent or contraception? PloS one 2013, 8(9):e73556.

17.Mujugira A, Heffron R, Celum C, Mugo N, Nakku-Joloba E, Baeten JM, Partners Pr EPST: Fertility intentions and interest in early antiretroviral therapy among East African HIV-1-infected individuals in serodiscordant partnerships. Journal of acquired immune deficiency syndromes 2013, 63(1):e33-35.

18. Harrington EK, Newmann SJ, Onono M, Schwartz KD, Bukusi EA, Cohen CR, Grossman D: Fertility intentions and interest in integrated family planning services among women living with HIV in Nyanza Province, Kenya: a qualitative study. Infectious diseases in obstetrics and gynecology $2012,2012: 809682$.

19.Kongnyuy EJ, Ngassa P, Fomulu N, Wiysonge CS, Kouam L, Doh AS: A survey of knowledge, attitudes and practice of emergency contraception among university students in Cameroon. BMC emergency medicine 2007, 7:7.

20.Alio AP, Daley EM, Nana PN, Duan J, Salihu HM: Intimate partner violence and contraception use among women in Sub-Saharan Africa. International journal of gynaecology and obstetrics: the official organ of the International Federation of Gynaecology and Obstetrics 2009, 107(1):35-38.

21.Ngianga-Bakwin K, Stones RW: Birth intervals and injectable contraception in sub-Saharan Africa. Contraception 2005, 71(5):353-356.

Page $9 / 10$ 
22. Consolidated guidelines on the use of antiretroviral drugs for treating and preventing HIV infection

[http://apps.who.int/iris/bitstream/10665/85321/1/9789241505727_eng.pdf?ua = 1]

23. Countdown to zero: Global Plan towards the elimination of new HIV infections among children by 2015 and keeping their mothers alive /http://www.unaids.org/sites/default/files/en/media/unaids/contentassets/documents/unaidspublication/2011/20110609_JC2137_Global-Plan-EliminationHIV-Children_en-1.pdf]

24.Cameroon DHS, 2011, Final Report /http://dhsprogram.com/publications/publication-FR260-DHS-Final-Reports.cfm\#sthash.GuL7n7oj.dpuf]

25. Rapport National de Suivi de la Declaration Politique sur le VIH/SIDA Cameroun: Global Aids Response Progress (GARP)

/http://www.unaids.org/sites/default/files/country/documents/CMR_narrative_report_2014.pdf]

26.Fusi-Ngwa CK, Payne VK, Asakizi AN, Katte BF: Knowledge and practice of family planning in Dschang municipality, Cameroon. African journal of reproductive health 2013, 17(1):137-148.

27. Haider TL, Sharma M: Barriers to family planning and contraception uptake in sub-Saharan Africa: a systematic review. International quarterly of community health education 2012, 33(4):403-413.

28.Eyawo 0, de Walque D, Ford N, Gakii G, Lester RT, Mills EJ: HIV status in discordant couples in sub-Saharan Africa: a systematic review and meta-analysis. The Lancet Infectious diseases 2010, 10(11):770-777.

29.Plan Strategique National de la Santé de la Reproduction, Maternelle, Neonatal et Infantile (PSN/SRMNI) 2014-2020

30.Aksan AM: Effects of Childhood Mortality and Morbidity on the Fertility Transition in sub-Saharan Africa. Popul Dev Rev 2014, 40(2):311-329.

31.Zoung-Kanyi Bissek AC, Yakana IE, Monebenimp F, Chaby G, Akondeng L, Angwafor SA, Lok C, Njamnshi AK, Muna WF: Knowledge of Pregnant Women on Mother-to-Child Transmission of HIV in Yaounde. The open AIDS journal 2011, 5.25-28.

32.Kisakye P, Akena WO, Kaye DK: Pregnancy decisions among HIV-positive pregnant women in Mulago Hospital, Uganda. Culture, health \& sexuality 2010, 12(4):445-454.

33.Ngugi EW, Kim AA, Nyoka R, Ng'ang'a L, Mukui I, Ng'eno B, Rutherford GW, Group KS: Contraceptive practices and fertility desires among HIV-infected and uninfected women in Kenya: results from a nationally representative study. Journal of acquired immune deficiency syndromes 2014,66 Suppl 1:S75-81.

34.Gutin SA, Namusoke F, Shade SB, Mirembe F: Fertility desires and intentions among HIV-positive women during the post-natal period in Uganda. African journal of reproductive health 2014, 18(3):67-77.

35.Birhane T, Assefa Tessema G, Addis Alene K, Dadi AF: Knowledge of pregnant women on mother-to-child transmission of HIV in Meket District, Northeast Ethiopia. Journal of pregnancy 2015, 2015:960830. 